\title{
Does the use of various population parameters affect fish assemblage structures?
}

\author{
Tadeusz Penczak* \\ Department of Ecology and Vertebrate Zoology, Faculty of Biology and Environmental Protection, University of Łódź, 12/16 Banacha \\ Str., 90-237 Łódź, Poland
}

Received: 28 June 2017; Accepted: 11 December 2017

\begin{abstract}
While studying the fish populations in small streamlets and their responses to climate change and anthropogenic stress, the following parameters are used: present/absent species, relative number, and relative biomass recently. Although the image/structure of the population differ from these parameters, this problem has not been investigated by researchers in this topic. It is now known that the potential energy accumulated in animal tissues is the best indicator of his strength and importance in nature, but I have not encountered work assessing the image of population structure according to these population parameters. Consequently, most reliable parameter - the relative calorific value of biomass (in the wet weight), was used. Relative biomass is the parameter of the population, which was found to be the closest to the calorific value of the biomass, as demonstrated by the SOM (self-organizing map) artificial neural network algorithm used in this study. For this reason, attempts have been made to convince authors of future work that relative biomass studies are used in the studies of fish assemblages, as research has already been undertaken, and this paper provides evidence that this choice is justified.
\end{abstract}

Keywords: Fish assemblage structures / present/absent / relative number / relative biomass / relative biomass caloricity

\section{Introduction}

The complex relationship between abiotic and biotic factors leads to many assemblages, which differ in their composition. An assemblage must be more than a random collection of species able to survive in a given area (Allan, 1995). The availability of adequate food for species is one of the most important factors governing the composition and stability of an assemblage, and the caloric content of the body is one of the important factors deciding about the composition and stability of populations within an assemblage (Beugly and Pyron, 2010).

The similarity of the structure of assemblages of fish in inland waters is assessed using two parameters: the species present/absent and relative number (Matthews, 1998), plus also recently the relative biomass (Penczak et al., 2005). The introduction of the new parameter concerning the relative calorific value is justified by the validity of the potential energy in the ecosystem and the species that inhabit it (Tytler and Calow, 1985) and, accordingly, the growth of vertebrates has been constrained by the limited supply of potential energy

\footnotetext{
*Corresponding author: tadeusz.penczakt@biol.uni.lodz.pl
}

(Allan, 1995). A noticeable mistake is that one judges the validity of a species in an assemblage by comparing, for example, an individual stickleback (about $1-3 \mathrm{~g}$ body weight) with a sexually mature pike or roach (weighing hundreds or even thousands of grams). Despite this fact, a few papers have been published in which the relative biomass of fish was used for assemblages' analysis instead of the relative number but without showing how assemblage will be looking when it will be made by the use of a caloric value (Kruk, 2006; Kruk et al., 2007; Penczak, 2011b; Kruk and Penczak, 2013; Penczak et al., 2013).

In temperate zones, fat levels increase in fish tissues before winter, and during spawning. However, this has no negative impact on our current research, as fish were caught in the same month. Also in the Dobrzynka Stream all fish species have a similar percentage of fat in the body (Penczak et al., 1977). However, there are fish species with higher levels of fat in tissues such as Anguillidae, Salmoninae, Coregoninae, or Thymallinae in Central European rivers, which may produce large numbers of populations, and the differences between biomass and body calories may be much larger, and can provide different of the assemblages dislocation in respective SOM's neurons, However, relative biomass and relative body caloricity will still remain most close to each other. 


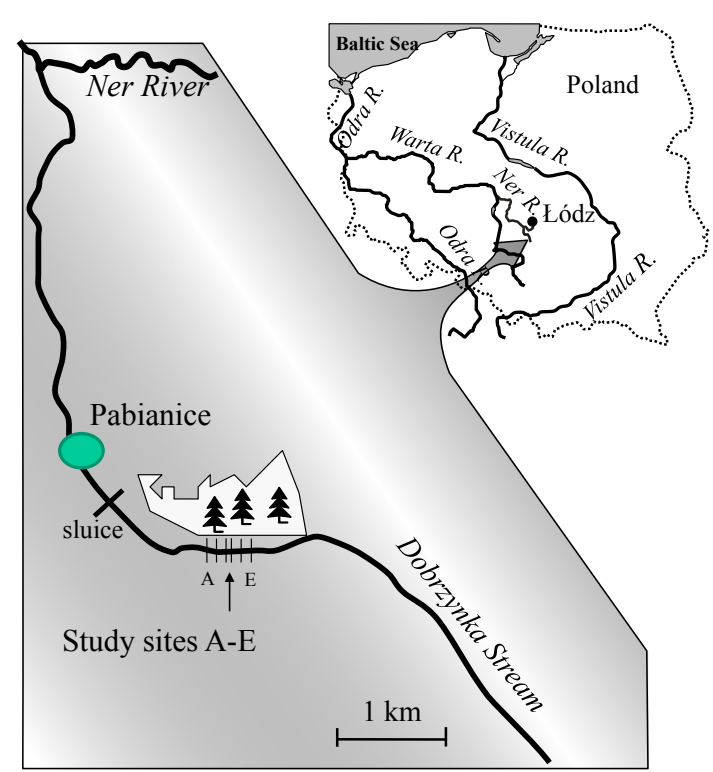

Fig. 1. Map of the study area and position of sites (A-E).

The aim of the study is to show which among used at present population parameters have a structure similar to the one obtained by the biomass caloricity.

\section{Study area}

The Dobrzynka Stream selected for the study is a left-side tributary of the Ner River in the Warta River system, Poland (Fig. 1). The length of the stream is about $21 \mathrm{~km}$ and its catchment is mostly meadows adjoining the banks, but there is occasionally arable land and forest in the source section. The Dobrzynka Stream, from its sources down to Pabianice, which the stream enters at the $15 \mathrm{~km}$ of its course, was slightly polluted by domestic sewage and occasionally by several farms distributed along its upper course.

The stream reach investigated was natural and meandering during 1979-1988, which is the period of the study. In 1989 the reach was regulated with two cement low-head dams and the period after 1989 is ignored to avoid the destructive impact of the dams on the formation of a fish assemblage (Penczak and Kruk 2005; Penczak et al., 2009).

Two rifles (each up to $10 \mathrm{~m}$ long) and ten pools (all being shallow enough for wading during sampling) occurred within the natural reach. The mean water discharge on the days of sampling (in each October of 1979-1988) was $0.15 \mathrm{~m}^{3} \mathrm{~s}^{-1}$ $\left(0.10-0.26 \mathrm{~m}^{3} \mathrm{~s}^{-1}\right)$. This stream can be considered a typical lowland one because the dominant breeding group in it are phytophilic fish species, and the only lithophil is a species of lamprey (Tab. 1). Mean water and air temperatures during the 10 years of study measured in October were respectively 13.0 ${ }^{\circ} \mathrm{C}$ (range: $9-13.4^{\circ} \mathrm{C}$ ), and $16.2^{\circ} \mathrm{C}$ (range: $9.5-25^{\circ} \mathrm{C}$ ).

\section{Materials and methods}

The fish were sampled each year at the end of their growing season (October, between 1979 and 1988). In October freshwater fish in central Europe achieve maximum body weight, body caloricity and mean biomass of populations, etc. in the given year (Penczak et al., 1982). During winter only decreases in the values of these parameters of fish individuals and fish populations have been recorded (Wootton, 1985).

The scientific name and English name of fish species, and their abbreviations, are in Table 1, whereby each species is organized according to its reproductive guild (Balon, 1990).

This study is based on one run/catch conducted on a CPUE basis (catch per unit of effort and consistent length of the river bank, the same electro shocker, two-anode dipnet; data used in the present study were not used in our former publications devoted of the Dobrzynka Stream fishes (Penczak, 2011b).

Fish were obtained in the course of the electrofishing by two people wading upstream with anode-dipnet, using a fullwave rectified current supplied from a $3 \mathrm{~kW}$ generator with an output of 220-230 V and 1.5-3.0 A at the dip-nets (Penczak, 1981). The fish were caught in five adjacent sites, each $100 \mathrm{~m}$ long, with the exception of the middle one, which was $50 \mathrm{~m}$ long; the whole study section was thus $450 \mathrm{~m}$ (Fig. 1, see sites A-E). The study used results obtained from the first catch only, and the average relative number and relative biomass were calculated from five sites in $100 \mathrm{~m}^{2}$.

Measurements of the energy content were made using a non-adiabatic calorimeter micro bomb (Klekowski and Bęczkowski, 1973), and pellets prepared from homogenates of whole fish were used (Penczak et al., 1982). Knowledge of the percentage of the water content in tissues and the caloric content of the dry mass of fish made it possible to calculate the energy content in the wet weight of fish species present in the stream to calculate the relative biomass (Penczak et al., 1984). Caloric content can only be measured in the dry matter in the micro bomb, but in bioenergetic papers it is given in both dry or wet mass. Such studies are expensive, but data on the body caloricity of plants and animals are available in literature (Cummins and Wuycheck, 1971).

A Kohen self-organizing map (SOM) was applied for ordering data (see Tab. 3) using the SOM Toolbox for Matlab version 6.1.0.450; implementation the SOM algorithm developed by the Helsinki University Technology (Vesanto et al., 2000; Kohonen, 2001; Céréghino and Park, 2009). The advantage of this method is that it can be used to effectively analyze complex data sets despite non-linear relationships and non-normal distributions, and it results in a two-dimensional map that is easy to interpret (Kohonen, 2001). The method has been commonly used for data analysis in various fields, including ecology, agriculture, health, and climate and engineering (Chon, 2011). The SOM has been proven to be an effective and powerful tool for exploring patterns in species' distributions and the structure of plants and animal communities, and the presence of each of the samples in the same neuron states do not differ significantly with the relevant parameter values used for its creation (Chon et al., 1996; Giraudel and Lek, 2001; Penczak et al., 2005, 2009; Kruk, 2006, 2007; Kalteh et al., 2008; Bedoya et al., 2009; Jutagate et al., 2011; Stojkovic et al., 2013).

The number of input neurons is equal to the number of variables in the data set, such as the number of years (10). Each input neuron is connected to all of the output neurons. During the training process, input neurons transmit signals to the output layer of neurons; with the data being 16 taxa $\times 10$ years. Times in the rough training phase and in the finetuning phase, 
Table 1. Reproductive guilds, according to Balon (1990), of fish and lampreys collected in the Dobrzynka Stream in the period 1979-1988.

\begin{tabular}{|c|c|c|c|}
\hline Guild & Scientific name & English name & Abbreviation \\
\hline \multicolumn{4}{|c|}{ Nonguarding and open substratum egg scattering } \\
\hline \multirow{4}{*}{ Phytolitophils } & Perca fluviatilis L. & perch & Pfluv \\
\hline & Esox lucius L. & pike & Lluci \\
\hline & Tinca tinca $(\mathrm{L})$. & tench & Ttinc \\
\hline & Carassius carassius (L.) & crucian carp & Ccara \\
\hline \multirow{4}{*}{ Phytophils } & Cyprinus carpio $\mathrm{L}$. & carp & Ccarp \\
\hline & Misgurnus fossilis (L.) & mud loach & Mfoss \\
\hline & Cobitis taenia $\mathrm{L}$. & gudgeon & Ggobi \\
\hline & Nemacheilus barbatulus (L.) & loach & Nbarb \\
\hline \multicolumn{4}{|c|}{ Nonguarding and brood hiding } \\
\hline Litophils & Eudontomyzon mariae (Berg) & Ukrainian lamprey & Emari \\
\hline \multirow{3}{*}{ Ariadnophils } & Gasterosteus aculeatus L. & stickleback & Gacul \\
\hline & Pungitius pungitius (L.) & ten-spined & Ppung \\
\hline & & stickleback & - \\
\hline
\end{tabular}

Table 2. Quantization and topographic errors for four population's parameters estimated in seconds (each at 100 epoch) for rough training phase has length 12 and for finetuning phase - 48; training phases were equal.

\begin{tabular}{lll}
\hline Population parameter & Quantization error & Topographic error \\
\hline Species present/absent & 0.911 & 0.000 \\
Relative number & 0.886 & 0.000 \\
Relative biomass (in g) & 0.913 & 0.000 \\
Relative body caloricity & 0.941 & 0.000 \\
(in KJ wet weight) & & \\
\hline
\end{tabular}

with the final quantization error $(\mathrm{QE})$ and final topographic error (TE), are presented in Table 2. Errors QE and TE gradually decrease with the increasing map size (Céréghino and Park, 2009) and, in turn, are important for undertaking a decision about the proper map size.

Output layers of different sizes were examined step by step, from $2 \times 2$ ( 4 neurons) to $5 \times 4$ (20 neurons), and an output layer of $4 \times 3$ (12 neurons) was ultimately chosen. It was noted that the determination of the optimum map size can be problematic, and equally that the SOM dimension is arbitrary (Céréghino and Park, 2009). One dimension of the SOM was selected for evaluating the similarity distribution of samples for the four analysed in this study's population parameters, as the level of the SOM can change the deployment trials in neurons.

To finally select a map size we used the heuristic rule by Vesanto et al. (2000): where map units are $5 \sqrt{n}$ and $n$ is the number of training samples. The actual neuron numbers should be close to the number determined by Vesanto et al.'s rule, but we have accepted a slightly smaller map $(4 \times 3,12$ neurons $)$ instead of 15 neurons $(5 \times 3)$, calculated from the heuristic rule, because there were still 5 empty units (units without assigned samples). However, this procedure does not yield clear gradients and is not relevant for other statistical analyses (Céréghino and Park, 2009), hence our decision.

The log transformed biomass of individuals (normalized $0-1)$ was presented onto the neurons in the input layer. A batch training algorithm has been used, which is significantly faster and does not require specification of any learning rate factor, and the results of the batch algorithm are not dependent on the learning order of inputs (Park et al., 2006). Generally, the SOM is a robust and useful method for ecological study (Kalteh et al., 2008; Chon, 2011), and different training functions do not have any noticeable effect on its operation (Noori et al., 2010).

\section{Results}

The degree of similarity of the SOM for relative body caloricity $(\mathrm{RBC})$ to the other three parameters (present/absent (PA), relative number $(\mathrm{RN})$, and relative biomass $(\mathrm{RB})$ ) were investigated using 10 samples collected in the years 19791988. All the maps were in the form of 4 rows $\times 3$ columns of neurons which made it possible to identify relevant similarities between the four population parameters. Output data for the four population parameters have been included in Table 3 . Maps made for $\mathrm{RBC}$ and $\mathrm{RB}$ are most similar in the arrangement of identical samples in the same neurons (Fig. 2); the samples which are inside a given neuron do not differ at a significant level in terms of a given population parameter. Without exception, samples from 1979 to 1983 for parameters are deployed in neurons $\mathrm{c} 1-\mathrm{c} 3$ and $\mathrm{d} 1-\mathrm{d} 3$ in maps for $\mathrm{RBC}$ and 
Table 3. Output data of population parameters used in the study (results from five connected sites): PA - presence-absence, RN - relative number, $\mathrm{RB}$ - relative biomass (in $\mathrm{g}$ ), $\mathrm{RBC}$ - relative body caloricity (in $\mathrm{KJ}$ of wet weight). Averages for five sites recalculated per $100 \mathrm{~m}^{2}$. Acronyms for species are given in Table 1 in the legends.

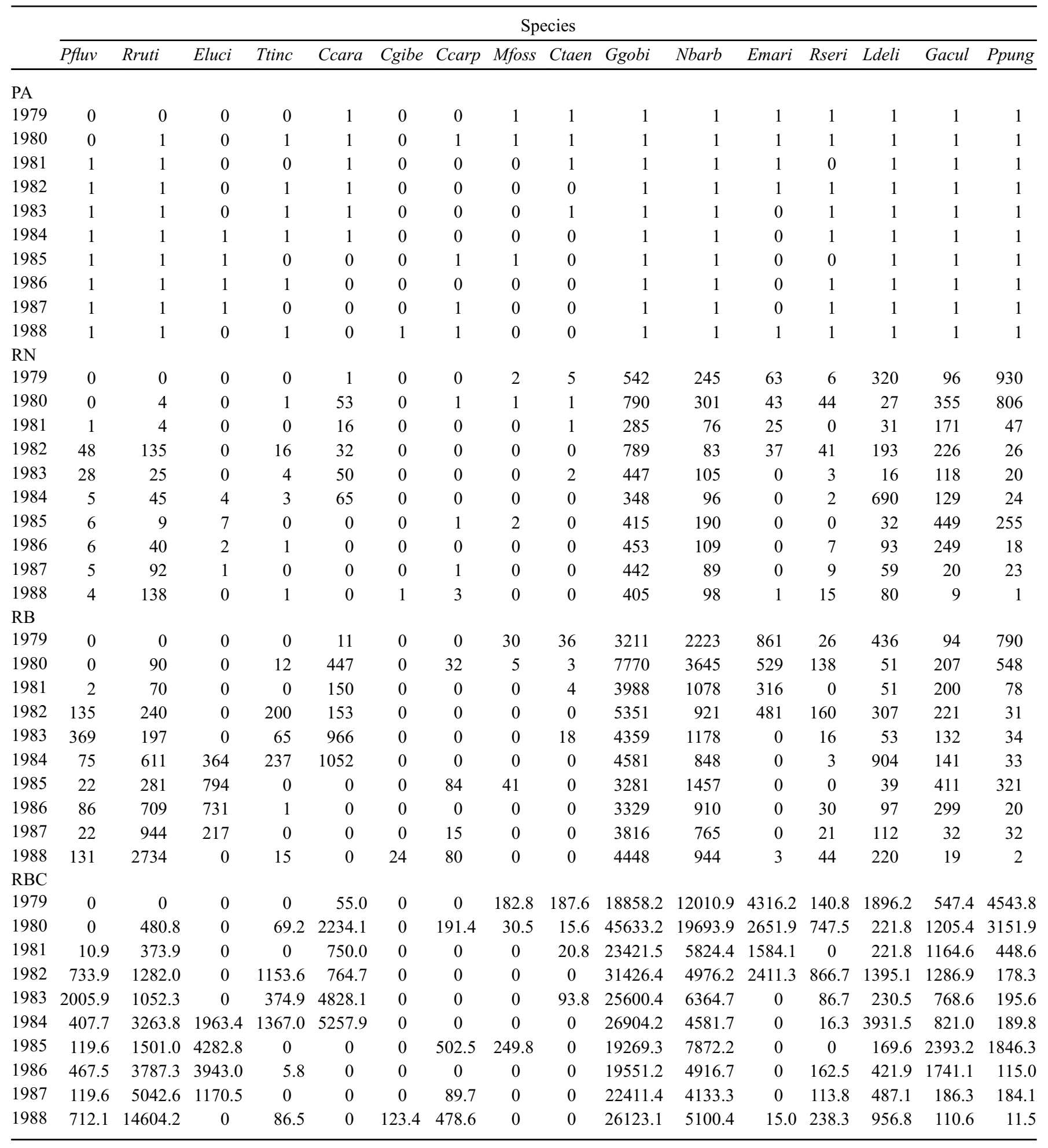

$\mathrm{RB}$, whilst in maps for PA and $\mathrm{RN}$ these samples are arranged very differently (Fig. 2, Tab. 4).

Some problems, however, can be found in the top rows (a1-a3, b1-b3), and this applies to all four maps. However, the smallest differences were recorded between $\mathrm{RBC}$ and $\mathrm{RB}$, because samples 1984 (a1), 1985 (b3) and 1987 (a3) in both of these compared maps are in the same neurons. However, between the RB and RBC only two samples (1986 and 1988) of 

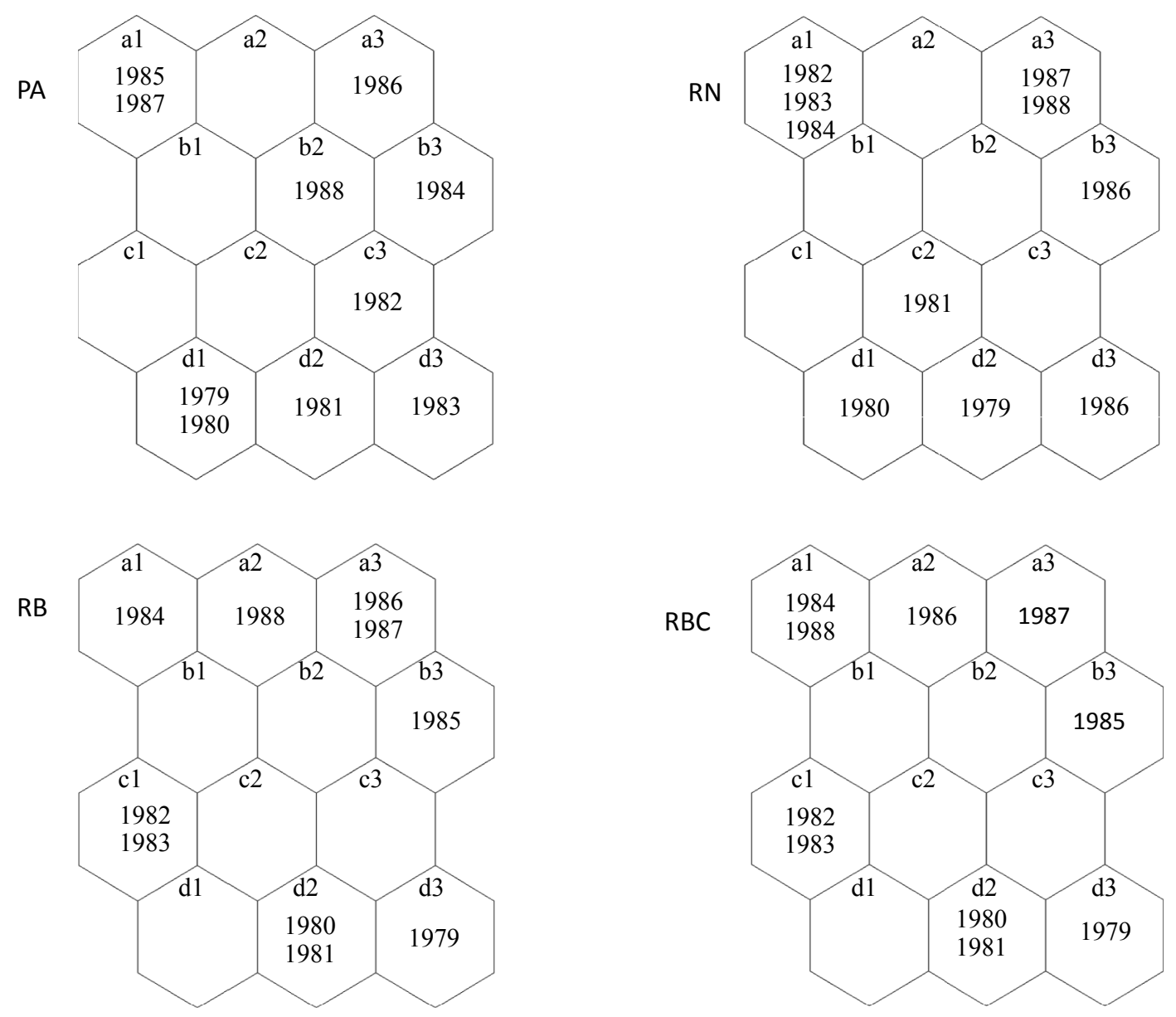

Fig. 2. SOMs formed by 12 hexagons $(4 \times 3)$ representing neurons as indicated by years of sampling data. SOMs created using: PA - present/ absent, RN - relative number, RB - relative biomass and RBC - relative body caloricity. Initial data: see Table 3.

Table 4. Number of samples on SOMs made for parameters: PA, RN and $\mathrm{RB}$ which occupy the same position * as in the SOM for RBC (Fig. 2), and ** number of samples located in adjacent directly neurons as these in RBC. Explanations: PA - species present /not, RN - relative number, $\mathrm{RB}$ - relative biomass, and $\mathrm{RBC}$ - relative body caloricity.

\begin{tabular}{llll}
\hline Population parameters & PA & RN & RB \\
\hline Number of samples * & 1 & 2 & 8 \\
Number of samples $* *$ & 1 & 1 & 2 \\
\hline
\end{tabular}

row ' $a$ ' moved to adjacent neurons in the same row (Fig. 2), thus indicating a significant similarity between these two compared maps. Besides, only maps for RB and RBC blank neurons are the same: b1, b2, c2, c3, and d1.

\section{Discussion}

I have no objection to different measures of abundance or biomass being applied for investigating assemblage structures of investigated populations in such groups that are uniform in body size, such as Entomostraca, Acarina, Pseudoscorpioni- dae, Eriophyidae, Pseudoscorpionidae, Cladocera, Acarina, Chironomidae and Acrania, etc.

Studies on the formation and stability of fish assemblages have been conducted for a long time now and literature on the subject was already quite rich during the end of the last century (Matthews, 1998). The last important factor in this study is monitoring, as evidenced by the creation of several scientific journals noting this in their titles. Most of these studies are based on one sample/catch which allows for a so-called relative number and the comparative reliability of this parameter increases when sampling is based on the constant CPUA (catch per unit of effort). The value of such research increases if you use the same equipment to obtain samples (in our case the fish in the rivers) taken from the same place and same time periods/intervals, paying attention to the longevity of the surveyed individual species. In the case of fish, which differ considerably in body size, some researchers began using the relative biomass in their studies instead of the relative abundance (Penczak and Kruk, 2005; Penczak et al., 2005; Kruk, 2006; Penczak, 2011a; Kruk and Penczak, 2013; Stojkovic et al., 2013). Weighing fish in field conditions is no longer expensive, and the fish of a given species can also easily be counted before releasing them back to river water, and without exposing them to any harm. Another parameter for auditing fish rather than the relative abundance was noted in a 
book by Tytler and Calow (1985), dedicated to fish energetics and the little representative abundance of any given sample; for example, $1 \mathrm{~g}$ body weight of stickleback and $100 \mathrm{~g}$ of pike or any other of large-bodied fish species. If, according to Tytler and Calow (1985), the best known parameter is the potential energy stored in a population's tissue, it is necessary to check how the structure of an assemblage's population will look when we apply parameters: species present or not (incidence), relative number, or relative biomass. These results show that the relative body biomass is among the three tested parameters most similar to the relative body calorific value. SOMs constructed for RBC and RB were most similar to each other, and could be replaced by the relative biomass. To be more specific, this is possible when the SOM methodology is applied, because samples that are inside the same neuron (represented by a hexagon - a graphic unit built by SOM) do not significantly differ in species' composition or their abundance values (Kalteh et al., 2008; Céréghino and Park, 2009; Noori et al., 2010; Chon, 2011; Penczak, 2011a).

The fish body caloricity parameter was first used and tested on fish, and it is revealed that this important parameter gives an image of a fish assemblage that is similar to that obtained from the use of relative biomass, and this does not change the cost of the research done so far.

Acknowledgement. I thank Dr Richard Johnson (Canterbury, UK) for the correction of the English of the study. I also thank Łukasz Głowacki (University of Łódź) for helpful comments and for final English correction. I am obliged to the Anonymous Reviewers for valuable comments, and critical remarks. The fish sampling for the study was supported by the University of Łódź (car of our University and support staff from our Department).

\section{References}

Allan JD. 1995. Stream ecology. Structure and function of running waters. UK: Chapman and Hall, 431 p.

Balon EK. 1990. Epigenesis of an epigeneticist: the development of some alternative concepts on the early ontogeny and evolution of fishes. Guelph Ichth Rev 1: 1-48.

Bedoya D, Novotny V, Manolakos ES. 2009. Instream and off stream environmental conditions and stream biotic integrity. Importance of scale and site similarities for learning and prediction. Ecol Model 220: 2393-2406.

Beugly J, Pyron M. 2010. Temporal and spatial variation in the longterm functional organization of fish assemblages in a large river. Hydrobiologia 654: 215-226.

Céréghino R, Park YS. 2009. Review of the self-organizing map (SOM) approach in water resources: Commentary. Environ Model Softw 24: 945-947.

Chon TS. 2011. Self-organizing maps applied to ecological sciences. Ecol Inform 6: 50-61.

Chon TS, Park YS, Moon KH, Cha EY. 1996. Patternizing communities by using an artificial neural network. Ecol Model 90: 69-78.

Cummins KW, Wuycheck JC. 1971. Caloric equivalents for investigations in ecological energetics. Mitt Int Ver Limnol 18: 1-158.
Giraudel JL, Lek S. 2001. A comparison of self-organizing map algorithm and some conventional statistical method for ecological community ordination. Ecol Model 90: 69-78.

Jutagate T, Lek S, Sawusdee A, et al. 2011. Spatio-temporal variations in fish assemblages in a tropical regulated lower river course: an environmental guild. River Res Appl 27: 47-58.

Kalteh AM, Hjorth P, Berndtsson R. 2008. Review of the selforganizing map (SOM) approach in water resources: Analysis, modelling and application. Environ Model Softw 23: 835-845.

Klekowski R, Bęczkowski J. 1973. A new modification of microbomb calorimeter. Ekol Pol 21: 229-238.

Kohonen T. 2001. Self-organizing maps. Third Extended Edition. Berlin: Springer.

Kruk A. 2006. Self-organizing maps in revealing variation in nonobligatory riverine fish in long-term data. Hydrobiologia 553: 4357.

Kruk A. 2007. Long-term changes in fish assemblages of the Widawka and Grabia Rivers (Poland): pattern recognition with a Kohonen artificial neural network. Int J Lim 43: 253-269

Kruk A, Penczak T. 2013. Natural regeneration of fish assemblages in the Pilica River after reduction of point source pollution. River Res Appl 29: 502-511.

Kruk A, Lek S, Park YS, Penczak T. 2007. Fish assemblages in the large lowland Narew River system (Poland): Application of the self-organizing map algorithm. Ecol Model 203: 45-61.

Matthews WJ. 1998. Patterns in freshwater fish ecology. New York: Chapman and Hall, Int. Thomson Publ., 756 p.

Noori R, Karbassi A, Sabahi MS. 2010. Evaluation of PCA and Gamma test techniques on ANN operation for weekly solid waste prediction. J Environ Manage 91: 767-771.

Park YS, Tison J, Lek S, Giraudel JL, Coste M, Delmas F. 2006. Application of a self-organizing map to select representative species in multivariate analysis: a case study determining diatom distribution patterns across France. Ecol Inform 1: 247-257.

Penczak T. 1981. Ecological fish production in two small lowland rivers in Poland. Oecologia (Berl.) 48: 107-111.

Penczak T. 2011a. Usefulness of the SOM for estimation of species distribution and significance in comparing hyabitats. J Appl Ichth 27: $1371-1374$.

Penczak T. 2011b. Fish assemblages composition in a natural, then regulated stream: a quantitative long-term study. Ecol Model 222: 2103-2118.

Penczak T, Kruk A. 2005. Patternizing of impoundment impact (1985-2002) on fish assemblages in a lowland river using the Kohonen Algorithm. J Appl Ichth 21: 169-177.

Penczak T, Molińaki M, Kusto E, Ichniowska B, Zalewski M. 1977. The ecology of roach, Rutilus rutilus (L.) in the barbel region of the polluted Pilica River. III. Lipids, protein, total nitrogen and caloricity. Ekol Pol 25: 75-88.

Penczak T, Suszycka E, Moliński M. 1982. Production, consumption and energy transformation by fish populations in a small lowland river. Ekol Pol 30: 111-137.

Penczak T, Kusto E, Krzyzanowska D, Molińsk M, Suszycka E. 1984. Food consumption and energy transformations by fish populations in two small lowland rivers in Poland. Hydrobiologia 108: 135-144.

Penczak T, Kruk A, Park YS, Lek S. 2005. Patterning spatial variation in fish structures and diversity in the Pilica River system. In Lek S, Scardi M, Verdonschot PFM, Descy JP, Park YS, eds. Modelling Community Structure in Freshwater Ecosystems, pp. 100-113, Berlin, Heidelberg, New York: Springer-Verlag. 
Penczak T, Agostinho AA, Gomes LC, Latini JD. 2009. Impacts of a reservoir on fish assemblages of small tributaries of the Corumbá River, Brazil. River Res Appl 25: 1013-1024.

Penczak T, Głowacki Ł, Kruk A, Galicka W. 2013. The role of streams of different sizes in recovery of fish fauna in the Pilica River catchment. River Res Appl 30: 1034-1047.

Stojkovic M, Simic V, Milosevic D, Mancev D, Penczak T. 2013. Visualization of fish community distribution patterns using the selforganizing map: A case study of the Great Morava River system (Serbia). Ecol Model 248: 20-29.
Tytler P, Calow P, eds. 1985. Fish energetics, new perspective. London, Sydney: Croom Helm, 349 p.

Vesanto J, Himberg E, Alhoniemi E, Parhankangas J. 2000. SOM Toolbox for Matlab 5. In: Technical Report A57, Helsinki, Finland: Neural Networks Research Centre, Helsinki University of Technology.

Wootton RJ. 1985. Energetics of reproduction. In Tytler P, Calow P, eds. Fish energetics, new perspective. pp. 231-254. London, Sydney: Croom Helm.

Cite this article as: Penczak T. 2018. Does the use of various population parameters affect fish assemblage structures? Ann. Limnol. - Int. J. Lim. 54: 10 